debilitated patients, and to overcome concerns about increased workloads by improving clinician user interfaces.

The study by Ure et al. ${ }^{1}$ is a welcome addition to a growing body of literature that invites health researchers to expand their horizons beyond the confines of single methods, and to embrace the richness of insights offered by the combination of qualitative and quantitative tools, particularly when tackling complex areas such as the evaluation of telemonitoring during the management of chronic diseases. By abandoning the methodological zealotry of the past which has forced researchers to pledge exclusive allegiance to qualitative or quantitative approaches, we might begin to assemble a holistic view of the myriad pieces that make telemonitoring whole and that can only become apparent when sought through multiple lenses and perspectives. Otherwise, we will be condemned to continue reporting a litany of unsophisticated implementation efforts which have gone awry.

Conflicts of interest The authors declare that there are no conflicts of interest in relation to this article.

Commissioned article; not externally peer-reviewed; accepted 7th February 2012; online 29th February 2012

C 2012 Primary Care Respiratory Society UK. All rights reserved

http://dx.doi.org/10.4104/pcrj.2012.00023

Prim Care Respir J 2012: 21(1): 10-11

\section{References}

1. Ure J, Pinnock H, Hanley J, Kidd G, McCall Smith E, Tarling A, Pagliari C, Sheikh A, MacNee W, McKinstry B. Piloting tele-monitoring in COPD: a mixed methods exploration of issues in design and implementation. Prim Care Respir J 2012;21(1):57-64 http://dx.doi.org/10.4104/pcrj.2011.00065

2. Chaudhry SI, Mattera JA, Curtis JP et al. Telemonitoring in patients with heart failure N Engl J Med 2010; 363: 2301-09. http://dx.doi.org/10.1056/NEJMoa1010029

3. Klersy C, De Silvestri A, Gabutti G, Regoli F, Auricchio A. A meta-analysis of remote monitoring of heart failure patients. J American College Cardiology 2009;54:168394. http://dx.doi.org/10.1016/j.jacc.2009.08.017

4. Inglis SC, Clark RA, McAlister FA, et al. Structured telephone support or telemonitoring programmes for patients with chronic heart failure. Cochrane Database Syst Rev 2010 (Online) CD007228 http://dx.doi.org/10.1002/14651858.CD007228.pub2

5. Koehler F, Winkler S, Schieber M, et al. Telemedicine in heart failure: Pre-specified and exploratory subgroup analyses from the TIM-HF trial. Int J Cardiol 2011 (Epub ahead of print). http://dx.doi.org/10.1016/j.ijcard.2011.09.007

6. Seto E, Leonard KJ, Cafazzo JA, et al. Perceptions and Experiences of Heart Failure Patients and Clinicians on the Use of Mobile Phone-Based Telemonitoring. J Med Internet Res 2012;14(1):e25. http://dx.doi.org/10.2196/jmir.1912

7. Cafazzo JA, Leonard K, Easty AC, Rossos PG, Chan CT. Patient perceptions of remote monitoring for nocturnal home hemodialysis. Hemodialysis International 2010;14:471-7. http://dx.doi.org/10.1111/j.1542-4758.2010.00473.x

\title{
Lower respiratory tract infection in the community: prognosis predictably difficult to predict
}

\section{See linked article by Francis et al. on pg 65}

\section{Paul A Marsden ${ }^{\mathrm{a}}$ * Mark Woodhead}

a 5th year Specialist Trainee in Respiratory Medicine, Department of Respiratory Medicine, Manchester Royal Infirmary, Manchester, UK

a Honorary Clinical Professor of Respiratory Medicine and Consultant in General and Respiratory Medicine, Department of Respiratory Medicine, Manchester Royal Infirmary, Manchester, UK

* Correspondence: Professor Mark Woodhead, Honorary Clinical Professor of Respiratory Medicine, Department of Respiratory Medicine, Manchester Royal Infirmary, Oxford Road, Manchester M13 9WL, UK. Tel: +44 (0)161 2764381

Fax: +44 (0)161 2764989 E-mail: mark.woodhead@cmft.nhs.uk

Community acquired pneumonia (CAP) is a leading cause of morbidity, with an annual incidence estimated at 5-11 per thousand adult population (higher in the young and the elderly). The diagnosis of CAP in hospital is made with a chest radiograph. In the community, the diagnosis relies upon a combination of symptoms suggestive of an acute lower respiratory tract infection (LRTI), presence of signs on chest examination, and systemic features (e.g. temperature $>38.0$ deg C). Diagnosing CAP in the community setting is therefore more problematic. ${ }^{1}$ In all settings the primary aim when treating CAP is to prevent death. Whilst mortality due to CAP in adults managed in the community in the UK is low $(<1 \%)$, this is higher in patients admitted to hospital (5.7-14\%) and higher still at 5-year follow-up (35.8-39.1\%).

In order to identify patients at both high and low risk of mortality, CAP severity scores have been developed to complement clinical judgement. The CURB-65 score, ${ }^{2}$ endorsed by the British Thoracic Society (BTS), consists of five elements - Confusion; Urea [>7mmol/l]; Respiratory Rate [ $\geq 30$ breaths/min]; Blood pressure [systolic $<90 \mathrm{mmHg}$ and/or diastolic $\leq 60 \mathrm{mmHg}$; age $\geq 65$ years - and has been shown in prospective studies to predict 30-day mortality in hospitalised patients with CAP. ${ }^{3-5}$ Recent systematic reviews and meta-analyses showed that CRB-65 (CURB-65 minus serum urea) is a useful indicator of severity in hospitalised patients, ${ }^{6}$ and in this group, equivalent to CURB-65 in predicting 30-day mortality.

Currently, clinical judgement in combination with CRB-65 is advocated in assessing the severity of CAP in community settings in the UK. ${ }^{8}$ Studies in support of this recommendation have included few patients in the community, ${ }^{9,10}$ and there is little data validating severity assessment tools in LRTI (without localising chest signs) in patients in primary care. The question therefore remains as to whether CRB-65 alone in this context accurately predicts patient outcomes.

The study by Francis et al. ${ }^{11}$ in this issue of the PCRJ set out to determine a) whether primary care clinicians routinely recorded elements of the CRB-65 score and b) whether the score accurately predicted prognosis in adults with LRTI in the community. Primary care 
clinicians in 13 European countries, including 14 primary care networks, completed a case record form (CRF) on initial patient assessment. Patients completed a daily diary from presentation until symptom resolution (or up to 28 days, whichever came first). Patients $\geq 18$ years old were included with an illness of $\leq 28$ days duration with cough (acute or worsened) or features suggestive of a LRTI. Each element of the CRB-65 was scored to assess compliance of clinicians with the score, and a Cox proportional hazards model was used to determine the association between an elevated CRB-65 score $(\geq 1)$ and prolonged illness.

Of the 3,368 subjects included ( $n=524[15.6 \%] \geq 65$ years old), $2,690(79.9 \%)$ had diary data available with 2,468 (73.3\%) having data at recovery. The authors were able to calculate CRB-65 scores for only $339(12.6 \%)$ study subjects, but by imputing zero for missing components of the CRB-65 score, created an additional dataset of 2,690 subjects. A clinical diagnosis of pneumonia was made in 111 subjects; however, a complete CRB-65 score was only available for 12 in this group. No subject had a CRB-65 score higher than 2 ( $n=9$ [2.7\%]) with the majority scoring 0 ( $n=235$ [69.3\%]). Interestingly, the authors report wide variation in scores between primary care networks. Regression analysis of the complete dataset found that a CRB-65 score $\geq 1$ was associated neither with a prolonged moderately severe illness (OR 0.42 [95\% Cl 0.04-4.19]), nor with hospitalisation (OR 3.12 [95\% Cl 0.16-60.24]).

This study has major strengths. Firstly a large, multinational primary care population was studied. Secondly, each primary care network contributed large numbers of subjects ( $>100$ in all but one centre) suggesting that this population is reflective of primary care across Europe. Thirdly, standardised methodology and data collection were used. There is, however, a large amount of missing data, confirming that clinicians do not regularly record each element required to calculate a CRB-65 score. The authors are probably correct in assuming that clinicians are less likely to measure and record normal variables; the attribution of a zero score for missing variables may be correct, but it does add another unnecessary variable to the study. The authors may therefore have missed a real effect, resulting in a type 2 error. Additionally, the subjects studied were young ( $n=524$ [15.6\%] $\geq 65$ years old) and therefore the findings of this study may not be applicable to an older population. Moreover, the endpoints were not the same as in previous CRB-65 studies. The validity of the scores in patients admitted to hospital is based on their ability to predict mortality. The causes of death may not be the same as the causes of prolonged illness nor of admission to hospital, so the premise that CRB-65 might work using a different endpoint may be flawed. Variation in scores between networks also questions the similarity of patient recruitment between networks.

Most studies using CRB-65 as a predictor of outcome are in either secondary care or in both primary and secondary care. Additionally, most studies include chest radiograph infiltrates as one of the subject entry criteria. One study, carried out in primary care in the Netherlands, ${ }^{12}$ used a logistic regression model to examine predictors of a combined endpoint of hospitalisation and death. The authors studied 3,166 episodes of LRTI (defined as pneumonia [with chest radiograph infiltrates], acute bronchitis and exacerbations of COPD) in an older population (mean age 75.5 years). They found that a combination of age $\geq 80$ years, presence of congestive cardiac failure or diabetes, use of oral glucocorticoids, hospitalisations in the previous year and antibiotic use the previous month, were the best predictors. The same group then studied the CRB-65 score in CAP in an older population (mean age 77.3 years) in the community. They demonstrated in this study that the CRB-65 score was equally as good as CURB-65 at predicting 30-day mortality in this subject group. ${ }^{10}$

More research is needed to confirm whether the CRB-65 score genuinely has value in managing CAP in the community as other studies have suggested. ${ }^{9,10}$ The main value for a general practitioner (GP) might be in predicting who should be referred to hospital. This does not mean that the CRB-65 should necessarily be used in all adults where CAP is suspected, but it might be especially useful in those where there is uncertainty about whether hospital referral is in the patient's best interests.

The study by Francis et al. ${ }^{11}$ importantly implies that CRB-65 may not be useful in predicting prolonged illness in adults with LRTI in primary care. The question of how to predict patient outcomes in LRTI in the community therefore remains unanswered. We hope that the authors of this study go on to use their data to help address this important unmet need.

Conflicts of interest The authors declare that there are no conflicts of interest in relation to this article.

Commissioned article; not externally peer-reviewed; accepted 23rd January 2012; online 23rd February 2012

(C) 2012 Primary Care Respiratory Society UK. All rights reserved

http://dx.doi.org/10.4104/pcrj.2012.00018

Prim Care Respir J 2012; 21(1): 11-13

\section{References}

1. Lim WS, Baudouin SV, George RC, et al. BTS guidelines for the management of community acquired pneumonia in adults: update 2009. Thorax 2009;64 Suppl 3:iii1-55. http://dx.doi.org/10.1136/thx.2009.121434

2. Lim WS, van der Eerden MM, Laing $R$, et al. Defining community acquired pneumonia severity on presentation to hospital: an international derivation and validation study. Thorax 2003;58:377-82.

http://dx.doi.org/10.1136/thorax.58.5.377

3. Buising KL, Thursky KA, Black JF, et al. A prospective comparison of severity scores for identifying patients with severe community acquired pneumonia: reconsidering what is meant by severe pneumonia. Thorax 2006;61:419-24. http://dx.doi.org/10.1136/thx.2005.051326

4. Man SY, Lee N, Ip M, et al. Prospective comparison of three predictive rules for assessing severity of community-acquired pneumonia in Hong Kong. Thorax 2007; 62:348-53. http://dx.doi.org/10.1136/thx.2006.069740

5. Barlow G, Nathwani D, Davey P. The CURB65 pneumonia severity score outperforms generic sepsis and early warning scores in predicting mortality in community-acquired pneumonia. Thorax 2007;62:253-9. http://dx.doi.org/10.1136/thx.2006.067371

6. McNally M, Curtain J, O'Brien KK, Dimitrov BD, Fahey T. Validity of British Thoracic Society guidance (the CRB-65 rule) for predicting the severity of pneumonia in general practice: systematic review and meta-analysis. Br J Gen Pract 2010; 60:e423-33. http://dx.doi.org/10.3399/bjgp10X532422

7. Chalmers JD, Singanayagam A, Akram AR, et al. Severity assessment tools for predicting mortality in hospitalised patients with community-acquired pneumonia. Systematic review and meta-analysis. Thorax 2010;65:878-83. http://dx.doi.org/10.1136/thx.2009.133280

8. Levy ML, Le Jeune I, Woodhead MA, Macfarlaned JT, Lim WS. Primary care 
summary of the British Thoracic Society Guidelines for the management of community acquired pneumonia in adults: 2009 update. Endorsed by the Royal College of General Practitioners and the Primary Care Respiratory Society UK. Prim Care Respir J 2010;19:21-7. http://dx.doi.org/10.4104/pcrj.2010.00014

9. Bauer TT, Ewig S, Marre R, Suttorp N, Welte T. CRB-65 predicts death from community-acquired pneumonia. J Intern Med 2006;260:93-101. http://dx.doi.org/10.1111/j.1365-2796.2006.01657.x

10. Bont J, Hak E, Hoes AW, Macfarlane JT, Verheij TJ. Predicting death in elderly patients with community-acquired pneumonia: a prospective validation study reevaluating the CRB-65 severity assessment tool. Arch Intern Med 2008; 168:1465-8. http://dx.doi.org/10.1001/archinte.168.13.1465

11. Francis NA, Cals JW, Butler CC, Hood K, Verheijc T, Little P, Goossense H, Coenen $S$ on behalf of the GRACE Project Group. Severity assessment for lower respiratory tract infections: potential use and validity of the CRB-65 in primary care. Prim Care Respir J 2010;21:65-70. http://dx.doi.org/10.4104/pcrj.2011.00083

12. Bont J, Hak E, Hoes AW, Schipper M, Schellevis FG, Verheij TJ. A prediction rule for elderly primary-care patients with lower respiratory tract infections. Eur Respir $J$ 2007;29:969-75. http://dx.doi.org/10.1183/09031936.00129706

\section{Asthma deaths: we need to identify risk factors early and construct at-risk asthma registers}

\section{See linked article by Anagnostou et al. on pg 71}

\section{*Paul Stephenson ${ }^{\mathrm{a}}$, Michael Shields ${ }^{\mathrm{b}}$}

a Honorary Clinical Research Fellow, Allergy and Respiratory Research Group, Centre for Population Health Sciences, The University of Edinburgh, Edinburgh, UK; Former Lead GP, UK Eastern Region Confidential Enquiry into asthma deaths

b Professor of Child Health \& Consultant Paediatrician (Respiratory), Centre for Infection \& Immunity, Queens University Belfast, N Ireland

*Correspondence: Dr Paul Stephenson, The Christmas Maltings and Clements Practice, Haverhill, Suffolk, CB9 8HF, UK Tel: c/o +44 (0)1461 600639 Fax: c/o +44 (0)1461 207819 E-mail: paul.stephenson@gp-d83012.nhs.uk

Studies into asthma deaths began in the 1960s in response to increasing mortality rates. ${ }^{1}$ Since then, various Confidential Enquiries and related reports from around the world ${ }^{2-7}$ have highlighted many factors - both medical management- and patient-related - which increase the risk of death in patients with asthma. Many of these are now well recognised, and have been incorporated into nationa $\left.\right|^{8}$ and international ${ }^{9}$ guidelines. The longest running Confidential Enquiry is based in the eastern region of the UK, ${ }^{6,7}$ and in this issue of the $P C R J$ Anagnostou et al. report on 20 deaths in children aged 17 or under (median age 11.5 years) which occurred between 2001 and 2006. ${ }^{10}$ The authors have done a great service in reminding us that people still die from asthma, and that some of these deaths - albeit rarely occur in children. The paper is also timely, since the 12-month UK Royal College of Physicians National Review of Asthma Deaths led by Mark Levy started on 1st February 2012.

Paediatric asthma deaths in the UK peaked in the mid-1960s with a mortality rate of 10 per million/year in the under-5s and 14 per million/year in children aged 5-14; rates then dropped to 2 per million/year in both age groups between 1990-2000. ${ }^{11}$ The eastern region of the UK has a population of approximately 5.25 million. Of the 20 childhood asthma deaths between 2001 and 2006, ${ }^{10}$ none of these were in children aged under 5; there were 13 deaths in the 5 14 age group, and seven in children aged 15-17. The absence of any deaths in the under-5s may simply be due to chance and the relatively small numbers involved, but our improved understanding (over the last 15 years) of the different diagnostic categories and more selective use of the term 'asthma' in this age group ${ }^{12,13}$ may also be a contributory factor.

Confidential enquiries have inherent methodological limitations; they are uncontrolled, retrospective and observational, and are more akin to audit or significant event analysis. Therefore the data need to be interpreted with caution. Nevertheless, the authors highlight a number of important points for clinicians and policy makers. ${ }^{10}$ Nine of the 20 children who died had mild to moderate asthma, 10 had severe asthma, and one had no previous diagnosis. This is a salutary reminder that death can occur in patients with mild or moderate disease (albeit that the risk of death in children with severe asthma is higher since the proportion with severe disease is much smaller ${ }^{14}$ ); seven out of the nine suffered sudden death, one was unwell for three days after a thunderstorm, and one suffered possible anaphylaxis after exposure to guinea pig. ${ }^{10}$ Two-thirds had documented poor adherence, and denial (either on the part of the patient or the parents) was a factor in two. The challenges of managing this patient group will be hard to address; most children who died did not have a written asthma action plan, and perhaps more attention should be given to this aspect of education - with more focus on acute crisis management - when dealing with someone with 'less troublesome' asthma.

A strength of this Enquiry is the emphasis on elucidating allergic factors involved in the patient's death; 13 of the 20 children had a clinical picture consistent with atopy, but only three had had formal allergy testing in an allergy clinic. 50\% died between June and August, and three deaths occurred during a thunderstorm. Furry pet animal dander was thought to be the trigger for four children. Together, these data highlight the need for clinicians to take a detailed allergy history (focussing on a range of external triggers) followed by appropriate testing when indicated. Unfortunately, we cannot tell whether prior allergy testing and knowledge about these allergies could have modified behaviour and prevented the deaths. The fact that half the deaths occurred in June to August suggests that clinicians should optimise therapy when the danger season approaches and ensure adherence with inhaled corticosteroid (ICS) treatment at appropriate doses. September and early October were not associated with high deaths, but there is an annual peak in asthma hospitalisation for younger children at this time ${ }^{15}$ which is 